IJBPAS, November, Special Issue, 2021, 10(11): 1233-1238

ISSN: 2277-4998

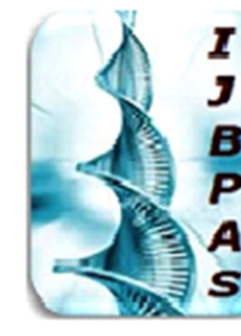

International Journal of Biology, Pharmacy and Allied Seiences (IJBPAS)

'A Bridge Betusen caboratory and Q Qnder'

www.ijbpas.com

\title{
COMBINED EFFECT OF YOGA PRACTICE WITH DIET ON CHOLESTEROL LEVEL AMONG OBESE WOMEN
}

\author{
MARINA RAI ${ }^{1^{*}}$ AND Dr. P. YOGA ${ }^{2}$ \\ 1: Research Scholar, Alagappa University College of Physical Education, Alagappa \\ University, Karaikudi, Tamilnadu, India \\ 2: Assistant Professor, Alagappa University College of Physical Education, Alagappa \\ University, Karaikudi, Tamilnadu, India \\ *Corresponding Author: Marina Rai; E Mail: marinarai808@gmail.com
}

Received $24^{\text {th }}$ July 2021; Revised $26^{\text {th }}$ Aug. 2021; Accepted $30^{\text {th }}$ Sept. 2021; Available online $1^{\text {st }}$ Nov. 2021

https://doi.org/10.31032/IJBPAS/2021/10.11.1106

\begin{abstract}
In this investigation, researcher made an effort to discover the Combined Effect of Yoga Practice with Diet on Cholesterol Level among Obese Women. For the point of investigation thirty obese women were chosen as subject randomly from Karaikudi, Tamilnadu, India and their age ranged from 25 to 35 years. The subjects selected for investigation was further split up into two groups of fifteen each. Group I acted as Yoga with Diet Group (Experimental Group) and Group II as control group. The experimental group was engaged in Yoga Practices programme for six weeks for duration of one hour and further, special diet was recommended to follow on regular basis for six weeks. On the contrary, the control group was not involved in any kind of special training in the course of the study. Cholesterol level was taken as criterion variable in this study. The Enzymatic Calorimetric Method (Laboratory Test) was used to test Cholesterol Level of the entire subject. Pre-test was taken before the training period and post-test was estimated right away after the six weeks of training period. Statistical technique ' $t$ ' ratio was employed to examine the means of the pre-test and post test data of experimental group and control group. The outcome of the study signifies that there was a significant difference detected on the criterion variable. The difference is found due to
\end{abstract}


six weeks of yoga practiceswith diet which was given to the experimental group on Cholesterollevel when compared to the control group.

Keyword: Cholesterol, Diet, Enzymatic Calorimetric Method, Obesity, Yoga, etc.

\section{INTRODUCTION}

Obesity is one of the serious growing medication problems suffering all over the world. Obesity leads to several other diseases such as diabetes, heart diseases, blood pressure, respiratory diseases and many more and it has taken much of life globally. It is caused by consuming high calories food. Today, people are more dependent on technology which has made life easy but at the same time living a passive life. Now a days, people rather prefer to take escalator or lifts then walking in stair case and making other things which has contribute to less physical activity and in result made people gain weight which ultimately lead to obesity. To lessen the percentage of obesity we should adopt physical activities more, such as yoga, aerobic dance or any other games where we can at least burn our calories and have a maximum movement or try to do a daily work routine without any help of machine.

Yoga favors a lot in terms of losing weight and toning up our muscles. The word Yoga, itself sounds very soulful and divine. Today, yoga is very trending among the people from old age to youngsters who want to run their life smoothly as it covers a broad range of benefits in human's life
[1]. It is exercise or practice which has come into the lime light since few years back and specially during COVID -19. Yoga has played a vital role during this 2019 pandemic. It has numerous benefits related to health, mind and spiritual. Yoga helps to build muscular energy, flexibility, coordination, balance, meditation and savasana, it helps to deep relaxation of body and mind. In addition, it helps to prevent the injuries [2]. Yoga has the answer for a healthy life vogue. It's a whole package with marvelous cardio, dynamic exercise, pondering posture and influence on one's behavior and life vogue [3]. As I already discuss we are living in a modern society, as the society is adapting new things we can see a lot of changes in our eating habit too, instead of cooking meal at home, we choose instant food or street food such as noodles, pizza, cholebhatoray, chat masala if we see around India which is prefer by most of the people. All this food is good in taste with no doubt but harmful at the same time. It would be a cherry on the cake if we practice a healthy diet and at the same time do yoga exercise, then we can see the adequate result on our health.Yoga is a 
system of exercises which helps the mind and body [4]. Yoga is a conventional and social study of India. Aside from yoga, India has contributed different sciences like Sanskrit language structure, arithmetic, kama sutra, and Ayurveda to the humankind. Ayurveda incorporates yoga as a piece of a perfect way of life and support of wellbeing [5]. The objective of yoga is solidarity of the body, brain and soul with the attention on body stance, breathing and contemplation. A few types of yoga exist to address the issues of differing ways of life and characters. Yoga is a great soul of the universe [6]. Yoga isn't just for the liberation of the brain, yet additionally for the unfaltering wellbeing [7]. Individual can start practicing Yoga at any time and age or a person may start with simple meditation or directly with breathing exercise (pranayama) without even doing the asana [8]. Asana can be used upon the needs of the person [9]. Yoga is a great soul of the universe [10].

\section{RESEARCH METHODOLOGY}

\section{Selection of subjects}

The study was design to discover the Combine Effect of Yoga Practice with Diet on Cholesterol Level among Obese Women. To attain the purpose of the study, thirty women were determined as subjects randomly from Karaikudi, Tamilnadu,
India. The age of the subjects were ranged from 18 to 25 years.

Selection of variable

\section{Independent variable}

Yoga Practice with Diet

\section{Dependent variable}

Cholesterol Level

\section{EXPERIMENTAL DESIGN AND IMPLEMENTATION}

The selected subjects were split up into two equal groups of fifteen subjects each, such as yoga practices with diet group (Experimental Group) and control group. The experimental group was engaged in yoga practices for four days per week for sixweeks with suggested diet on daily routine for six weeks as well. Control group, on the other hand were not involved in any special training programme apart from their regular physical activities as per their daily routine. The following dependent variable namely Cholesterol Level was selected as criterion variable. All the subjects of two groups were tested on selected criterion variable Cholesterol Level which was measured through Enzymatic Calorimetric Method (Laboratory Test) at prior to and straight away after the training programme.

\section{Statistical technique}

The ' $t$ ' test was applyto analysis the significant differences, if any, difference between the groups respectively.

\section{Level of significance}


The 0.05 level of confidence was fixed to test the level of significance which was considered as a relevant.

\section{ANALYSIS OF THE DATA}

The significance of the difference among the means of the experimental group was found out by pre-test. The data were analysed and dependent ' $t$ ' test was used with 0.05 levels as confidence.

The Table 1 shows that the mean values of pre-test and post-test of the control group on Cholesterol Level were 213.00 and 213.33 respectively. The obtained ' $\mathrm{t}$ ' ratio was 1.23 , since the obtained ' $t$ ' ratio was less than the required table value of 2.14 for the significant at 0.05 level with 14 degrees of freedom it was found to be statistically insignificant. The mean values of pre-test and post-test of the experimental group on Cholesterol Level were 213.53 and 200.80 respectively. The obtained ' $t$ ' ratio was $36.95 *$ since the obtained ' $t$ ' ratio was greater than the required table value of 2.14 for significance at 0.05 level with 14 degrees of freedom it was found to be statistically significant. The outcome of the study conveyed that there was a significant difference between control group and experimental group in Cholesterol Level. It may be concluded from the consequences of the study that experimental group improved in Cholesterol Level due to six weeks of Yoga Practices and suggested Diet.

Table I: Analysis of t-ratio for the pre and post tests of experimental and control group on Cholesterol Level

\begin{tabular}{|c|c|c|c|c|c|c|c|c|}
\hline \multirow[t]{2}{*}{ Groups } & \multicolumn{2}{|c|}{ Mean } & \multicolumn{2}{|c|}{ S.D } & \multicolumn{2}{|c|}{$\begin{array}{c}\text { Standard } \\
\text { error }\end{array}$} & \multirow[t]{2}{*}{ df } & \multirow[t]{2}{*}{ "tt" ratio } \\
\hline & Pre & Post & Pre & Post & Pre & Post & & \\
\hline Control & 213.00 & 213.33 & 1.41 & 1.39 & 0.36 & 0.36 & \multirow{2}{*}{14} & 1.23 \\
\hline Experimental & 213.53 & 200.80 & 1.30 & 1.26 & 0.33 & 0.32 & & $36.95 *$ \\
\hline
\end{tabular}

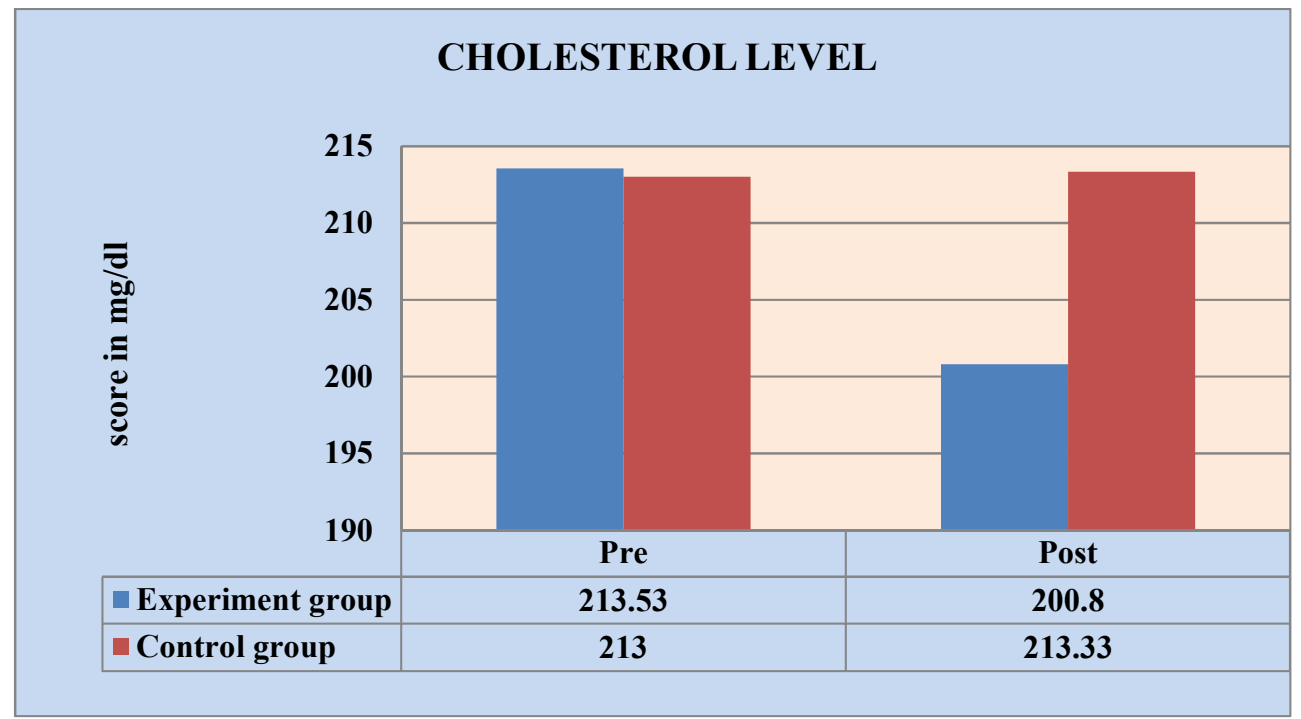

Figure 1: Bar Diagram Showing the Pre and Post Mean Values of Experimental and Control Group Cholesterol Level 


\section{DISCUSSIONS ON FINDINGS}

The interpretation of the study state that the experimental group, namely yoga with diet group had impressively improved the selected dependent variable, namelyCholesterol Level, when compared to the control group. It is observed that the improvement found in the experiment group was caused by yoga with diet when compared to the control group.

\section{CONCLUSION}

[2] Das, Sumitra., Yoga, P., Alaguraja, K., Selvakumar, K., \& Rai, Marina., Consequence of yoga and rowing. International journal of advanced science and technology, 29(03),2020, pp.7079-7084.

[3] Alaguraja, K., \& Yoga, P., Effect of yoga therapy on BMI rate among class I obese patient. Indian journal of public health research \& development, 11(05), 2020, pp.143-

On the basis of the consequences obtained from the study, the following conclusions are drawn,

1. There was a significant difference between experimental and control group on CholesterolLevel after the training period.

2. There was a significant improvement in Cholesterol Level. However the improvement was in favor of experimental group due to six weeks of yoga practice with diet.

\section{ACKNOWLEDGMENT}

The author thanks all the participants who had volunteer throughout the study.

\section{CONFLICT OF INTEREST}

Nil

\section{REFERENCES}

[1] Rai, Marina., Yoga, P., Alaguraja, K., Selvakumar, K., \& Das Sumitra., The power of yoga. International journal of advanced science and technology, 29(03),2020, pp.6225-6229.
[4] Rai, Marina \& Yoga, P., A scientific effect of yogic package on body mass index among class I obese, Journal of Information and Computational Science, 9(10),2019, pp.468-473.

[5] Rai, Marina \& Yoga, P., Efficacy of yogic therapy on high density lipoprotein among high school girls, Journal of Information and Computational Science, 9(10),2019, pp.455-459.

[6] Selvakumar, K., Parthasarathy, S., Rai, Marina., \& Das, Sumitra., The sun salutation practices on body mass index among rural school boys. International Journal of Sports, Health and Physical Education, 1(2) 2019, pp.01-04.

[7] Selvakumar, K., Parthasarathy, S., Rai, Marina., \& Das, Sumitra., 
Impact of yin yoga on body mass index among obese patients, International Journal of Sports, Health and Physical Education, 1(1) 2019, pp.17-20.

[8] Parthasarathy, S., Selvakumar, K., Rai, Marina., \& Das, Sumitra., Bikram yoga package on high density lipoprotein level, International Journal of Physical Education, Exercise and Sports, 1(2) 2019, pp.21-24.

[9] Selvakumar, K., James Rathinaraj, S., Rai, Marina., \& Das, Sumitra., Walking practices and Kundalini awakening on body mass index on middle school students, International Journal of Sports, Exercise and Physical Education, 1(2) 2019, pp.01-04.

[10] Parthasarathy, S., Selvakumar, K., Rai, Marina., \& Das, Sumitra., Analysis the effect of Ashtanga yogic package on low density lipoprotein among sports persons International Journal of Physical Education, Exercise and Sports, 1(2) 2019, pp.17-20. 